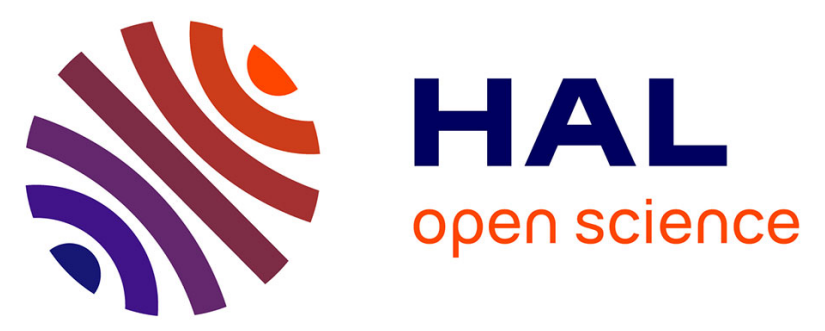

\title{
A simple 3D river/tidal turbine model for farm computation - Comparison with experiments
}

Vincent Clary, Thibault Oudart, Thierry Maître, Joël Sommeria, Wassim

Zeidan, Luis A Morocho, Ali Makhour, Philippe Larroudé, Tristan

Vandenberghe, Laure Vignal, et al.

\section{To cite this version:}

Vincent Clary, Thibault Oudart, Thierry Maître, Joël Sommeria, Wassim Zeidan, et al.. A simple 3D river/tidal turbine model for farm computation - Comparison with experiments. Sixth International Conference on Estuaries and Coasts (ICEC-2018), Aug 2018, Caen, France. hal-01897925

\section{HAL Id: hal-01897925 \\ https://hal.science/hal-01897925}

Submitted on 17 Oct 2018

HAL is a multi-disciplinary open access archive for the deposit and dissemination of scientific research documents, whether they are published or not. The documents may come from teaching and research institutions in France or abroad, or from public or private research centers.
L'archive ouverte pluridisciplinaire HAL, est destinée au dépôt et à la diffusion de documents scientifiques de niveau recherche, publiés ou non, émanant des établissements d'enseignement et de recherche français ou étrangers, des laboratoires publics ou privés. 


\title{
A simple 3D river/tidal turbine model for farm computation - Comparison with experiments
}

\author{
Vincent Clary*, Thibault Oudart, Thierry Maitre, Joel Sommeria, Wassim Zeidan, Luis A. Morocho, Ali \\ Makhour, Philippe Larroudé, Tristan Vandenberghe, Laure Vignal, Michel Riondet, Florence Joussellin.
}

\author{
Univ. Grenoble Alpes, Grenoble INP', LEGI, 38000 Grenoble, France \\ ${ }^{l}$ Institute of Engineering Univ. Grenoble Alpes
}

Mathieu Rodriguez, Khoa Borzeix

CERG, 38800 Le Pont-de-Claix, France

Olivier Bertrand, Julien Schaguene

Artelia Eau \& Environnement, 38130 Echirolles, France

\begin{abstract}
A simple CFD modeling using force source terms in the momentum equation is implemented, with the aim of computing the performance of a Darrieus turbine in its exploitation area and simulating the wake created behind the turbine. It uses the RANS solution method to reproduce ambient turbulent flow conditions with relatively low computational costs. The force distribution used is three-dimensional and has been calculated prior to implementation using a single URANS simulation of the flow through the real geometry of the turbine. To take into account the velocity and turbulent conditions of the flow impacting the turbine, forces can be corrected by the total forces obtained experimentally on a reduced-scale model for different flow cases. The impact on the turbine of upstream turbulence generated by a grid is studied experimentally. The power coefficient, drag force and transverse component of the force on the turbine are studied, as well as the shape and extension of its wake using Particle Imaging Velocimetry. Simplified models with different levels of detail are compared to the experimental data. The results turn out to be in good agreement in the far-wake, with an underestimation of the flow deficit in the near-wake.
\end{abstract}

Key words: Array power production; Turbine wake; Cross-flow hydrokinetic turbine; Vertical axis stream turbine

\section{Introduction}

Tidal or river stream turbine technology is currently undergoing rapid progress. The first prototypes have been installed and tested in oceans as well as in rivers. In a site with high potential (i.e. high tidal or river currents), the position of turbines related to each other has to be calculated, for the optimization of their efficiency and impact studies. The turbine performance and the size of the wake must be computed efficiently. Two main generic turbine shapes exist nowadays: vertical axis turbines, for example the Darrieus model tested at LEGI by Maitre et al. (2013), and horizontal axis turbines like the model tested in Southampton by Myers and Bahaj (2006). The method presented here aims at developing a simple 3D turbine model for farm computations by means of experimental studies and numerical developments. It can be applied to any kind of turbine, but

\footnotetext{
* Corresponding author. Email: vincent.clary@univ-grenoble-alpes.fr
}

results are presented in this work for a vertical axis turbine.

Various studies have been undertaken recently to develop models of stream turbine arrays. For axial turbines, analytical methods based on the Betz-Joukowsky law (the Actuator Disk method) have been improved to take into account confinement of stream turbines under water, due to the presence of the bathymetry, free surface and the other adjacent turbines (Garett and Cummins, 2007; Whelan et al., 2009). The models were extended to an array of tidal stream turbines by Vennell (2013) or Draper and Nishino (2014).

Detailed CFD simulations of different turbines have been performed, taking into account the impact of the local velocity of the flow on a turbine. RANS simulations of a farm containing 4 axial tidal stream turbines, have been performed by Nuernberg and Tao (2018) with relevant results but relatively high computational costs. Concerning vertical axis turbines, efficient unsteady RANS simulations using a SST turbulence closure model were carried out by 
Kinsey and Dumas (2017), yet without studying the farwake.

To properly model all the eddies characterizing the wake of a turbine in operating conditions, LES simulations of a single turbine can be performed with a turbulent inlet velocity profile. Posa et al. (2016) conducted LES simulations of vertical axis wind turbines, and the wake structure was found to be in good agreement with experiments. Concerning the modelling of axial tidal stream turbine arrays, interactions between 3 turbines in tri-frame configuration were simulated using the LES method by Chawdharry et al. (2017).

The aforementioned simulations have a high computational cost, therefore simplified CFD models are being developed in an industrial context. Using them, it is possible to consider many turbines at real sites and provide a practical tool for the optimization of the turbine positions. At the oceanic scale, large domains and long durations are computed thanks to $2 \mathrm{D}$ models, in order to simulate properly the effects of the tides at a potential site all along the year. Two different approaches exist to compute the effect of a tidal turbine: it can be modeled by a friction force on the bottom (Vogel et al., 2017), or by adding a force source term in the momentum equations (De Dominicis et al., 2017), with significantly the same results. Three-dimensional simulations might be useful to take into account the bathymetry more precisely. Wimshurst and Willden (2016) showed using an Actuator Disk (AD) approach that a turbine at a location where water depth is diminishing (in the current direction) produces less power than the same turbine at a location with increasing water depth. This is due to modifications in the boundary layer, as turbines are often placed in elevations that are still impacted by the velocity reduction in the bed boundary layer. Using the $3 \mathrm{D} A D$ method is simple enough to simulate large turbine arrays, whilst also taking turbulence into account using RANS turbulence models (Harrison et al., 2009; Roc et al., 2013). For the axial turbine, different turbulence models (KEpsilon, K-Epsilon Realizable, RSM, K-Omega-SST) have been tested by Nguyen et al. (2016) and produced different results. The authors proposed to add a source term in the turbulence equations to improve the results but the value must be chosen properly. In another study, Laan (2014) modified the K-Epsilon equations to get accurate results for wind turbine farms computation.

For vertical axis stream turbines, Gebreslassie et al. (2016) used the Actuator Cylinder approach, which is a modification to the $\mathrm{AD}$ method, applying also a transverse component of the force. Forces are applied to the hollow cylindrical zone swept by the blades. A very accurate description of the wake of a single turbine is obtained by setting the force value, still this force has to be determined precisely. It led to an interesting model of a whole farm of vertical axis tidal turbines (Gebreslassie et al., 2015).

In the Actuator Disk or Actuator Cylinder methods, results are very sensitive to the force (distribution and magnitude) representing the turbine. To determine the lift and drag force values exerted on the blades of a turbine, the Blade Element Momentum (BEM) approach can be used for the different types of turbines. Such methods were performed in 2D to model a vertical axis stream turbine (Dominguez et al., 2016). On this basis, a 3D model of a vertical axis turbine array has been computed in TELEMAC by Bertrand et al. (2015) and needs comparison with experiments.

The natural turbulence conditions of the flow impacting a turbine have also an influence that is still difficult to obtain numerically. Experiments of a reduced scale axial stream turbine in a free-surface channel showed that the length of the wake was more than two times shorter with a strong inlet turbulence intensity (15\%) than with a low inlet turbulence intensity (3\%) (Mycek et al., 2014). Still no study to our knowledge has addressed the influence of inlet turbulence intensity on vertical axis turbines. This point will be addressed in this work.

Turbulence also reduces the delivered power. Loads on the turbine can be affected significantly by the ambient turbulence properties. Shives and Crawford (2015) presented an axial turbine model using a non-uniform force distribution applied in the volume swept by the blades that also takes into account local velocity and free-stream turbulence. The force distribution is computed for different conditions with a 3D BEM method. Experimental data is used to correct the total force values, to take into account the Reynolds effects as well as the turbulence and inlet velocity conditions of the flow impacting the turbine in each case. Total force values are interpolated from the experimental data to correspond to the ambient flow conditions experienced in an operational site. This method provides good results with a few cells in the domain (9 per diameter of the turbine) and two turbines in a row have been computed.

In the present work, we investigate results of a 3D RANS simulation with a detailed force source field added in the momentum equation, including components in the three dimensions. It is demonstrated using a cross-flow turbine model already tested at LEGI. Experimental measurements are carried out at CERG hydrodynamic tunnel in order to examine the influence of upstream turbulence and velocity on the turbine loadings, efficiency and wake. The mean torque is measured, as well as forces in the streamwise and transverse directions. Inlet conditions are controlled by choosing to use a turbulence grid or not, and a characterization of the flow is performed in each case without the turbine, using Laser Doppler Velocimetry (LDV) measurements.

To analyze the results of the present simplified turbine model, a comparison with Particle Imaging Velocimetry (PIV) measurements of the wake of the cross-flow turbine is made. Various force distributions, ranging from the classical Actuator Cylinder model to a detailed 3D force distribution including force terms in the arm area are compared for the simplified model. 
The model is also implemented in TELEMAC, using the 3D non-hydrostatic solver with the K-Epsilon turbulence model, to check the ability of an oceanic code to reproduce the correct wake.

\section{Experimental setup}

The CERG hydrodynamic tunnel TH2 is used for the experiments. It is a closed loop where water is pumped by a propeller pump at velocities up to $6 \mathrm{~m} / \mathrm{s}$. Dimensions of the test section are $2.5 \mathrm{~m}$ long, $0.60 \mathrm{~m}$ wide and $0.555 \mathrm{~m}$ high, and it is preceded by a half-convergent in the bottom of the channel (Figure 1). At the end of the convergent section, a regular turbulence grid can be added $0.91 \mathrm{~m}$ upstream of the axis of the turbine. Positions are defined with a reference frame $(\mathrm{x}, \mathrm{y}, \mathrm{z})$, with $\mathrm{x}$ streamwise, $\mathrm{y}$ lateral and $\mathrm{z}$ vertical. The axis origin lies on the turbine axis, at mid-height of the turbine.

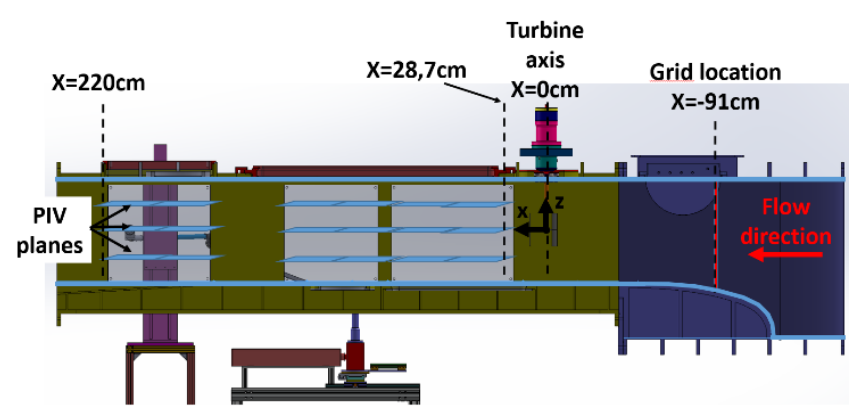

Figure 1: CAD view of the CERG hydrodynamic tunnel test section, with turbine, grid position, and PIV planes positions

To characterize the ambient flow, a first lateral window allows LDV-measurements of the velocity fluctuations without any turbine. Two cases are investigated: without any grid and with a regular turbulence grid whose bars are $12.5 \mathrm{~mm}$ thick with a mesh of $50 \mathrm{~mm}$ (Figure $3 \mathrm{~b}$ ). The laser2-focus technique is used, with two sets of two beams emitted, enabling measurements in $\mathrm{x}$ (streamwise) and $\mathrm{z}$ (vertical) directions. 2000 points are taken for each measurement, to obtain mean velocities and mean fluctuations of the velocity. The profile in the streamwise direction is measured in the middle of the channel, from $130 \mathrm{~mm}$ downstream of the turbine axis to $720 \mathrm{~mm}$ downstream of the axis. Profiles are presented in Figure 2 for the cases with and without the regular turbulence grid.

For measuring the level of turbulence, turbulence intensity is calculated using an assumption for v', the third component of the velocity fluctuation (y-component) that could not be measured.

The following assumption was made:

$v^{\prime 2}=\frac{u^{\prime 2}+w^{\prime 2}}{2} \Rightarrow$
$I t u r b \equiv \frac{\sqrt{\frac{1}{3}\left(u^{\prime 2}+v^{\prime 2}+w^{\prime 2}\right)}}{\sqrt{U_{x}^{2}+U_{y}^{2}+U_{z}^{2}}}=\frac{\sqrt{\frac{1}{2}\left(u^{\prime 2}+w^{\prime 2}\right)}}{\sqrt{U_{x}^{2}}}$

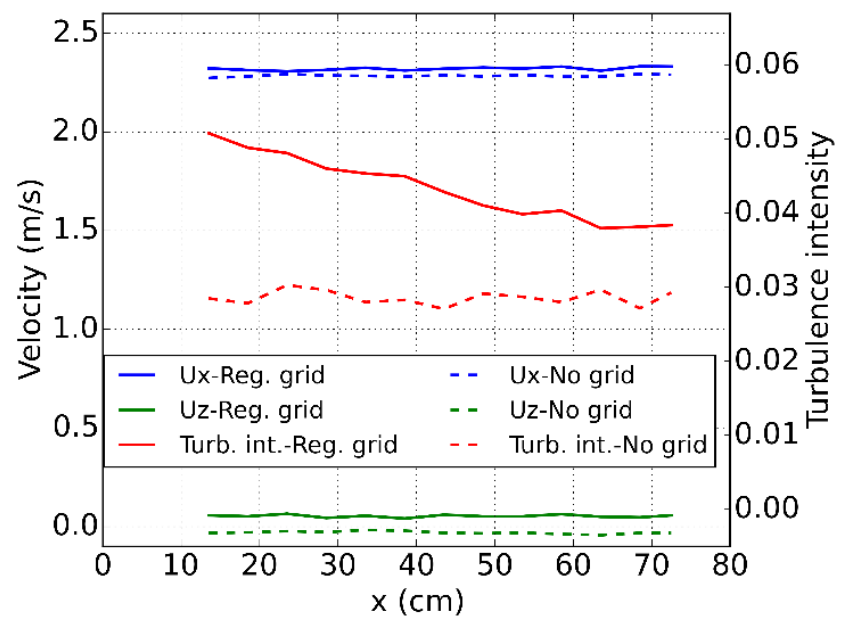

Figure 2: $x$-profile of measured mean $x$ and $z$ components of velocity, and turbulence intensity compared for the cases with and without the regular turbulence grid

Similar profiles were measured in the transverse directions. The velocity proves to be constant throughout most of the channel section, and the boundary layers extend up to $10 \mathrm{~cm}$ from the channel walls, guarantying that they do not influence the flow in the turbine area. However the turbulence intensity is not uniform in the $\mathrm{z}$ direction in the case without turbulence grid, even far from the channel walls. This is due to the shape of the asymmetric convergent section that creates more turbulence in the bottom. The turbulence intensity measured in Figure 2 is about $2.8 \%$. But values in other altitudes range from $2.0 \%$ to $3.0 \%$, therefore the value of $2.5 \%$ seems more representative and is chosen for the simulations. In the case of the turbulence grid, this problem does not appear because the grid is smoothing the turbulence intensity profile. A turbulence decay is observed. The turbulence intensity is extrapolated to find the value of $5.5 \%$ in the zone of the channel where the turbine can be placed.

The water velocity in the channel is controlled with a Prandtl probe, located approximately $170 \mathrm{~cm}$ upstream of the beginning of the convergent section. It was calibrated before the measurements using the LDV-results. The turbine used is a vertical axis water turbine with $n=3$ straight blades, with a diameter $\mathrm{D}=175 \mathrm{~mm}$ and a height of $175 \mathrm{~mm}$ (Figure $3 \mathrm{a}$ ). The blades are NACA0018 profiles, with a camber following a rotating circle of diameter $175 \mathrm{~mm}$. Its chord value is $\mathrm{c}=33 \mathrm{~mm}$, leading to a solidity $\frac{2 n c}{D}=1.1$. 

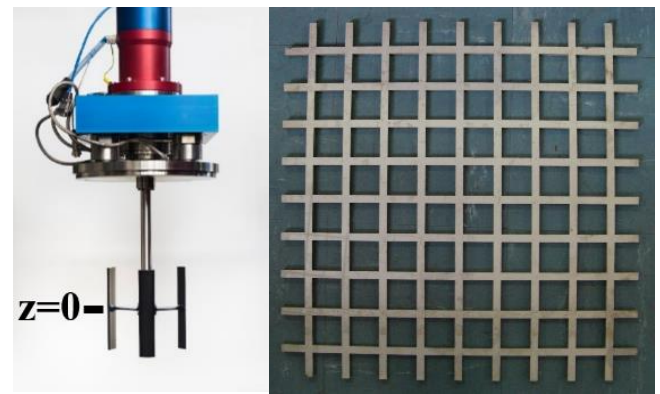

Figure -3a (left): Darrieus turbine used during the experiments with its shaft, motor and measurement system -3b (right): Regular turbulence grid used

The turbine is centered in $\mathrm{z}$-direction, and situated $5 \mathrm{~cm}$ to the right of the center of the channel in y-direction. Its rotational speed is controlled by an electric motor placed above the channel. The turbine is connected to the motor by a $22 \mathrm{~mm}$ diameter shaft. The regulation and measurement system is detailed in previous work (Aumelas, 2011). Piezoelectric sensors measure the instantaneous $x$ and $y$ force components applied to the whole turbine, with an absolute error estimated to be $\pm 3 \mathrm{~N}$ due essentially to a time drift. For each measurement, 4800 points are acquired with a frequency corresponding to one point per 3 degrees travelled by the turbine, which ensures an averaging time corresponding to 40 revolutions.

In the case with turbulence grid, the forces are measured for different channel velocities to observe the influence of Reynolds number. They are compared to forces obtained in the case without turbulence grid, for a channel velocity of $2.3 \mathrm{~m} / \mathrm{s}$, in Figure 4. Adimensional force coefficients are plotted, defined as

$$
C x=\frac{F x}{\frac{1}{2} \rho S U_{x}^{2}} ; C y=\frac{F y}{\frac{1}{2} \rho S U_{x}^{2}}
$$

In (eq. 2), the velocity Ux is measured via the Prandtl probe, and is time-averaged over 5 minutes to remove a nonnegligible noise due to the probe.

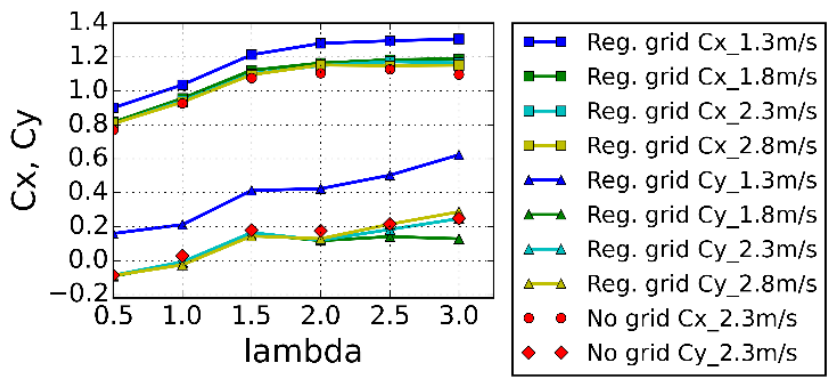

Figure 4 : $\mathrm{Cx}$ and $\mathrm{Cy}$ experimental measurements versus $\lambda$ for different inlet flow cases

The force coefficients are found not to be dependent on the Reynolds number anymore for inlet velocities equal to or higher than $2 \mathrm{~m} / \mathrm{s}$. Moreover, the turbulence grid has no significant influence for those velocities, therefore a sole value of the total forces will be used in the simplified model simulations for both turbulence cases.

The instantaneous total torque is obtained via the current measurement of the motor. Measured values are averaged over at least 5 revolutions of the turbine. The motor torque, $\mathrm{T}$, varies linearly with the current intensity, with a coefficient equal to $-1.38 \mathrm{Nm} / \mathrm{A}$ given by the manufacturer. It enables one to calculate the power coefficient $\mathrm{Cp}$ in each case, defined as:

$$
C p=\frac{T \Omega}{\frac{1}{2} \rho S\left(U_{x}\right)^{3}}(e q 3)
$$

The measured torque includes the mechanical friction of the bearings and the rubber seal, the latter having a large friction torque. Measurements of the friction torque are carried out 5 times without the turbine for different rotational speeds. The torque occurs to be approximately constant and equal to $-0.2 \mathrm{Nm}$. This value is subtracted to the measured torque to obtain a power coefficient of the turbine itself, independent of the mechanical components.

The turbine wake is measured with PIV. An injecting tube is placed approximately $1.2 \mathrm{~m}$ upstream of the turbulence grid position, with a variable injection height. $30 \mu \mathrm{m}$ diameter polyamide particles are used and are distributed regularly throughout the whole channel thanks to the turbulent dispersion. Horizontal planes, starting $0.29 \mathrm{~m}$ up to a maximum of $2.20 \mathrm{~m}$ downstream of the turbine (depending on the planes), allow to get measurements up to a maximum of 12 diameters downstream of the turbine. Plane 0 is located at mid-height of the turbine $(\mathrm{z}=0$ with $\pm 0.5 \mathrm{~cm}$ uncertainty regarding this position), then 5 planes are spaced above plane 0 with $+4 \mathrm{~cm}$ increment in $\mathrm{z}$ direction each time, and 5 planes are spaced the same way under plane 0 . Only the $\mathrm{x}$ and $\mathrm{y}$ velocity components are caught in the measurements.

One thousand pairs of images are taken for each measurement, and are synchronized with the key blade being in the most downstream position. This position is detected by a trigger, so that one image pair is taken each turbine revolution. The chosen time interval for an image pair is $600 \mu \mathrm{s}$, in order to capture the small velocities in the near wake, as well as higher velocities. For the far wake, a time interval of $800 \mu \mathrm{s}$ is used.

PIV results are post-treated with the UVMAT software, available in the internet page http://servforge.legi.grenobleinp.fr/projects/soft-uvmat.

\section{Numerical modelling}

The aim of the whole study is to get an accurate simplified CFD model in order to simulate the wake of a vertical axis stream turbine. In the simplified model, the geometry of the turbine is not modeled. Instead, force terms are added in the 3 components of the momentum equations 
for all cells included in the volume swept by the turbine. Simplified model simulations are stationary, and a timeaveraged force distribution is used in this volume, depending on the position of each cell. This force distribution has to be known. Shives and Crawford (2015) used a BEM method to get the force distribution for various flow velocities and turbulence conditions. In our case, we obtain a detailed force distribution for a unique case, and a correction is then applied to take into account flow velocity and turbulence conditions if they differ.

\section{Full geometry URANS simulation to obtain the load} distribution on the turbine

To compute this force distribution, a unique fullgeometry URANS simulation of the flow through the turbine is performed, with a chosen inlet flow velocity of $2.3 \mathrm{~m} / \mathrm{s}$ and a turbulence intensity of $2.5 \%$. This simulation is done with OpenFoam. The dimensions of the simulation domain correspond to the experimental dimensions with a section of $0.60 \mathrm{~m}$ wide, $0.555 \mathrm{~m}$ high and $2.5 \mathrm{~m}$ in the direction of flow $(0.5 \mathrm{~m}$ upstream, $2 \mathrm{~m}$ downstream of the turbine). To reduce the number of cells, a symmetry is used on the median plane $(\mathrm{z}=0)$. A RANS turbulence closure model is used with the $\mathrm{k}$ Omega Shear Stress Transport linear eddy viscosity equations (Menter, 1994 ; Menter et al., 2003). This model has two equations on $\mathrm{k}$ and $\omega$, and allows to capture correctly the flow separation. To capture the boundary layer flow near the turbine, a dimensionless wall distance $y+$ less than 5 (corresponding to a cell height of $2.0 \times 10^{-5} \mathrm{~m}$ near the wall) is used and extended within 10 layers. The turbine rotation is taken into account using a dynamic mesh interface between the tunnel and a cylinder containing the turbine. These specifics lead to a full mesh composed of 16 million cells.

The pimpleDyMFoam solver is used to get accurate results in acceptable time. It is a large time-step transient solver for incompressible, turbulent flow, using the PIMPLE (merged PISO-SIMPLE) algorithm and with the ability to take into account dynamic mesh. The numerical schemes used are second order (backward) for the time, and second order for pressure, velocity, $\mathrm{k}$ and omega (Gauss linear) with a limiter for $\mathrm{k}$ and omega. At $\lambda=2$, the time step is chosen to correspond to a rotation of 1 degree of the turbine with a maximum of 50 subiterations each time step. A lower time step is chosen for lower lambda values. Results are extracted only once 15 revolutions of the turbine have been completed.

To obtain a representative distribution of the turbine forces exerted on the flow, a time-averaged force field is extracted on a new cylindrical mesh. Its cells are the basic volume elements of a cylindrical coordinate system which does not rotate with the turbine (Figure 5). The decomposition is done here for the half of the turbine simulated, and will be extended later by symmetry to the whole turbine. The zone where blade forces are present is decomposed into one cell in the radial direction, 10 cells in $\mathrm{z}$-direction and 72 cells along the $360^{\circ}$ of $\theta\left(\mathrm{d} \theta=5^{\circ}\right)$. For the arms, forces are extracted in a domain that contains 10 cells in the radial direction, 1 cell in $\mathrm{z}$-direction, with $\mathrm{d} \theta=5^{\circ}$.

During the 15th revolution of the turbine, both arms and blades forces are extracted for every cells of this cylindrical referential, for each time step equivalent to $1^{\circ}$ rotation. This referential being fixed, at each time step, cells of the cylindrical mesh witness either a part of the blades or arms (in this case corresponding forces are extracted) or only fluid (no forces are extracted). At last, a time-averaging of those force distributions during the whole revolution is performed for each cell to obtain a stationary spatial distribution of the forces.

Simulations were done on a Xeon DELL C6320 with 20 cores and lasted 30 days for 15 revolutions.

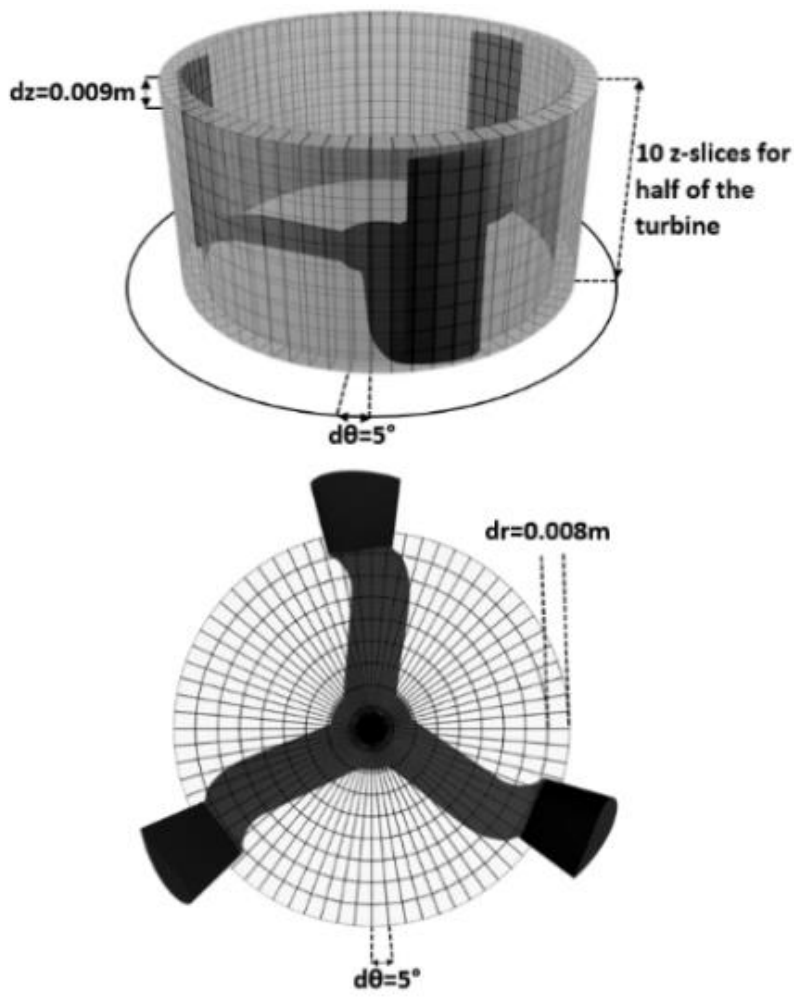

Figure 5: Cylindrical mesh used to compute the timeaveraged forces to be used in the simplified model simulations.

\section{Experimental correction for each inlet flow condition}

To take into account ambient flow conditions and have turbine performances conform to the experiment, the force distribution obtained with simulations is multiplied by a corrector $\mathrm{C}$, so that the total forces are equal to the total forces measured along $\mathrm{x}$ and $\mathrm{y}$ axis for each experimental case. The total force along $\mathrm{z}$ should be null due to the symmetry, and no correction is applied in that direction. In the simplified model, for each zone $\mathrm{i}$ of the decomposed domain, the $\mathrm{x}$-component of force applied is 


$$
\begin{aligned}
F_{x, i}^{\text {corrected }} & =\frac{F_{x, \text { tot }}^{\text {measured }}}{\sum_{i} F_{x, i}^{\text {not corrected }}} * F_{x, i}^{\text {not corrected }} \\
F_{x, i}^{\text {corrected }} & =C\left(I_{t u r b}, \lambda^{*}\right) * F_{x, i}^{\text {not corrected }}(\text { eq } 4)
\end{aligned}
$$

where $C$ depends on the advance parameter (or tip speed ratio) $\lambda$, and $I_{\text {turb }}$ is the ambient turbulence intensity. We have seen before that turbulence intensity plays no role in the total $\mathrm{x}$ and $\mathrm{y}$-forces, so that $\mathrm{C}$ only depends on $\lambda$ here. The $\mathrm{y}$ component of the force is corrected the same way.

In the future, it will be necessary to discuss how to choose the local velocity to compute the $\lambda$ parameter for each turbine of a farm.

\section{Simplified simulation setup}

The simplified model uses the RANS solution method, and has been coded both in OpenFoam and TELEMAC3D software. Only the case with the regular turbulence grid (corresponding to $5.5 \%$ turbulence intensity at turbine position) is presented here, for which the inlet turbulence properties are well controlled.

The OpenFoam simulation is done using the SimpleFoam solver. A classical resolution of the steady-state RANS equations is performed, and both K-Epsilon and KOmega-SST turbulence models are used in the simulations.

Telemac3D is a free surface software with a moving mesh following the free surface. The non-hydrostatic version of the code is used, solving the RANS equations in the three directions, plus adding a step for the free surface calculation in z-direction. Therefore the horizontal components and the vertical component are computed separately. The K-Epsilon turbulence model is used here in both the horizontal and vertical directions. The program uses a time-step resolution, even if a steady-state is simulated here.

The simulation domain is faithful to the tunnel size for the OpenFoam simulation, with a $3 \mathrm{~m}$ long domain with $0.6 \mathrm{~m}$ breadth and $0.55 \mathrm{~m}$ height. The domain starts $0.37 \mathrm{~m}$ upstream of the turbine to assure that the inlet uniform velocity condition does not affect the turbine calculation. The outlet condition used is of the InletOutlet type, and gives the same results as a simulation using a longer calculation domain.

For the TELEMAC simulation, the domain could not respect the experimental setup geometry. Indeed for a water height of $0.55 \mathrm{~m}$, the Froude number is 0.99 , leading to a transitional regime. Therefore the water height was increased to $2 \mathrm{~m}$. This does not introduce a significant error as the confinement is very low (section area of the tunnel is 10 times bigger than the turbine projected area). A channel length of $4.5 \mathrm{~m}$ is used to be sure that the outlet pressure condition has no influence on the wake computation. The inlet flowrate condition and outlet altitude condition (i.e. a hydrostatic pressure condition) are chosen. Due to the bottom friction, a small difference in altitude is observed, creating a velocity deficit in the inlet section. The velocity at inlet is therefore found to be $2.23 \mathrm{~m} / \mathrm{s}$ instead of $2.3 \mathrm{~m} / \mathrm{s}$.

In both cases, the mesh is refined near the walls. In the whole wake domain, the mesh is uniform and has cubic cells with sides of length $0.01 \mathrm{~m}$. This domain comprises at least $20 \mathrm{~cm}$ on each side of the turbine center in $\mathrm{y}$ and $\mathrm{z}$ directions, starts at inlet and continues until outlet in $\mathrm{x}$ direction. A cell size $d x=0.01 \mathrm{~m}$ enables one to have 17 cells along the diameter of the turbine.

In both codes, turbulence has to be set properly at the inlet. With the turbulence grid, turbulent kinetic energy and Epsilon or Omega values have to be set to obtain the correct turbulence intensity value at the turbine position, and the correct turbulence decay. Several iterations of simulations of the flow in the channel without any turbine were performed to properly set both values, and the final simulated turbulence decay at the channel center fits the experimental measurements (Figure 6). Both software give the same results. The TELEMAC code was implemented to impose properly inlet turbulence conditions.

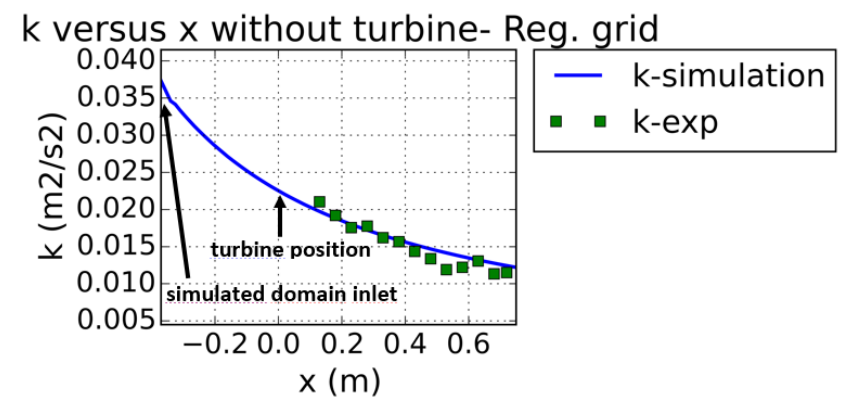

Figure 6 : Experimental and simulated turbulent kinetic energy (k) decay along $x$, in the center of the channel, without turbine

\section{The different simplified models used}

Different levels of simplification have been tested. As simulation times were far lower for the OpenFoam simulations, all models were implemented in that code whereas only model 2 was implemented in TELEMAC3D for comparison.

- Model 1 is the most detailed, with a non-uniform force distribution depending on the 3 directions all along the blade area and the arm area. Fx, Fy and Fz are considered in this model.

- Model 2 is a 2 dimensional detailed force distribution in the blades area only, depending on the angle but not on the altitude. $\mathrm{Fz}$ is not considered.

- Model 3 is a uniform distribution in the cylinder formed by the whole area swept by the turbine. Fz is not considered. 


\section{Results}

The power coefficient curves versus $\lambda$ proved to have a certain variability across the measurements. This might be explained by fluctuations of the velocity impacting the turbine. Therefore 5 curves were plotted each time, and the colored envelopes of the maximum and minimum values measured each time are shown in Figure 7, for various flow conditions. The cases with and without the regular grid are considered. We observe that the variability is larger for the case without the grid, where turbulence is less controlled. A strong Reynolds number influence is noticeable for the case without the grid at velocities under $2.3 \mathrm{~m} / \mathrm{s}$. This velocity is therefore chosen for future measurements. In both cases, the maximum $\mathrm{Cp}$ observed is close to 0.25 for $\lambda=1.75$ It has to be compared to the maximum $\mathrm{Cp}$ obtained for the fullgeometry URANS simulation, which is 0.26 for $\lambda=2$. The simulated values are in good agreement with the experimental values.
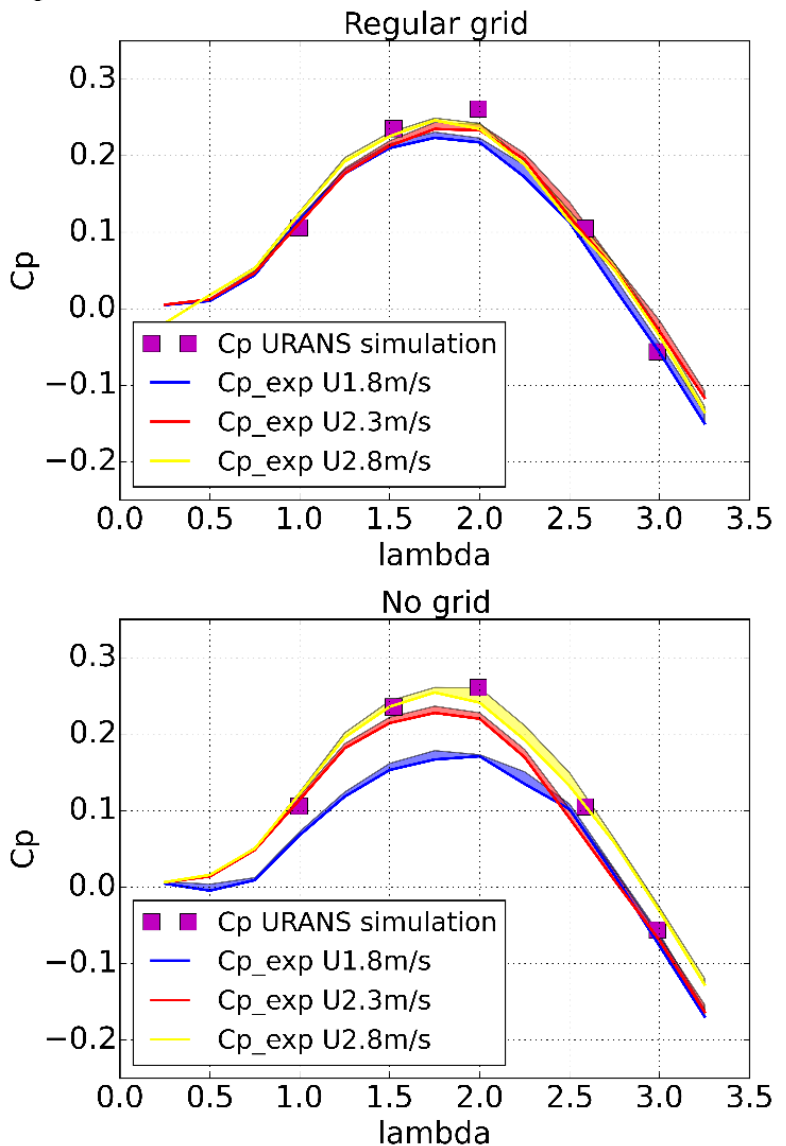

Figure 7: Experimental results at different channel speeds and URANS full geometry results for Cp versus $\lambda$

The $\mathrm{Cx}$ and $\mathrm{Cy}$ experimental measurements have already been presented in Figure 4. To determine the forces applied on the turbine without including its shaft, as done in the simulations, the drag exerted on the shaft must be subtracted. It is estimated using the drag coefficient formulae for an infinite cylinder. At the channel velocity of $2.3 \mathrm{~m} / \mathrm{s}$, the Reynolds number order is $10^{4}$, giving a drag coefficient value of 1.0 (corresponding to the turbulent area on the $\mathrm{Cd}$ curve). The calculated drag value is $F x_{\text {shafi }}=12.3 \mathrm{~N}$. The forces are compared to the URANS full-geometry simulation results in table 1 . A lift component should also be calculated, as the shaft is rotating. A first estimation referring to the work of Badalamenti and Prince (2008) gives an estimation of $-3 \mathrm{~N}$ that has not been considered here.

At $\lambda=2$, the simulated total forces are close to the experimental total forces measured, and the URANS simulation is in good agreement with the experiment. For lower and higher $\lambda$, the $\mathrm{x}$-component of force is correctly computed but the $\mathrm{y}$-component presents errors. Further investigations are needed to compare URANS results to experiments. It might appear that URANS simulations are sufficient to obtain the force distributions, saving a lot of instrumentation efforts.

Table 1: Total experimental forces compared to the total forces computed with URANS simulation

\begin{tabular}{|l|l|l|l|l|l|l|}
\hline & \multicolumn{2}{|c|}{$\lambda=\mathbf{1}$} & \multicolumn{2}{c|}{$\lambda=\mathbf{2}$} & \multicolumn{2}{c|}{$\lambda=\mathbf{3}$} \\
\hline $\mathbf{U = 2 . 3 m} / \mathbf{s}$ & $\mathbf{F x}(\mathbf{N})$ & $\mathbf{F y}(\mathbf{N})$ & $\mathbf{F x}(\mathbf{N})$ & $\mathbf{F y}(\mathbf{N})$ & $\mathbf{F x}(\mathbf{N})$ & $\mathbf{F y}(\mathbf{N})$ \\
\hline $\begin{array}{l}\text { Experimental } \\
\text { forces without } \\
\text { shaft correction }\end{array}$ & 74.7 & -0.6 & 91.2 & 9.6 & 92.4 & 19.6 \\
\hline $\begin{array}{l}\text { Shaft force } \\
\text { corrections }\end{array}$ & 12.3 & 0 & 12.3 & 0 & 12.3 & 0 \\
\hline $\begin{array}{l}\text { Input total forces } \\
\text { for the } \\
\text { simplified model }\end{array}$ & $\mathbf{6 2 . 4}$ & $\mathbf{- 0 . 6}$ & $\mathbf{7 8 . 9}$ & $\mathbf{9 . 6}$ & $\mathbf{8 0 . 1}$ & $\mathbf{1 9 . 6}$ \\
\hline $\begin{array}{l}\text { URANS } \\
\text { computed forces }\end{array}$ & 58.3 & -9.8 & 79.9 & 6.6 & 82.1 & 13.4 \\
\hline
\end{tabular}

Concerning the wakes, the PIV images taken for the cases with and without turbulence grid, at $\lambda=2$, present few differences. Plots of the mean velocity in the transverse direction at plane $0(\mathrm{z}=0 \mathrm{~cm})$ are presented in Figure 8 for both cases. The plots are presented for different positions downstream of the turbine (2 diameters downstream, 4 diameters downstream...). The velocity deficit is slightly larger in the near-wake for the case with the low turbulence level (without grid), and then tends to recover faster. But the curves are really close. The two ambient turbulence levels studied here are close $(2.5 \%$ and $5.5 \%)$ and explain the proximity of the results. Other measurements with a higher ambient turbulence intensity are needed to determine if this parameter impacts the wake as much as for axial turbines.

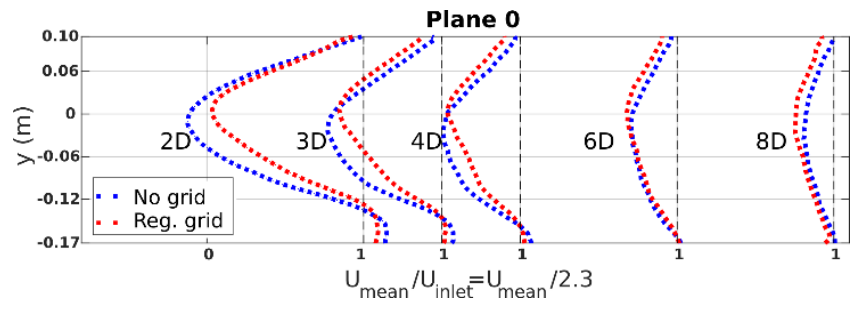

Figure 8 : Comparison of the transverse profiles of mean velocity obtained by PIV in plane 0 for the cases $\lambda=2$ 
A comparison was made between the wakes obtained with experiments, with the 3 simplified models implemented in OpenFoam, and with the simplified model implemented in TELEMAC. The OpenFoam simulations results are shown only with the K-Omega-SST model, but results proved to be the same with the K-Epsilon model for the cell sizes used in the simulations. Figure 9.a shows the axial mean velocities for all cases in a horizontal cross-section at the altitude of plane 1 (corresponding to the middle of the upper part of the blades). This is done at different positions downstream of the turbine (2 diameters downstream, 4 diameters downstream...). Vertical plots at $\mathrm{y}=0$ are also compared at the same positions downstream of the turbine on Figure 9.b.

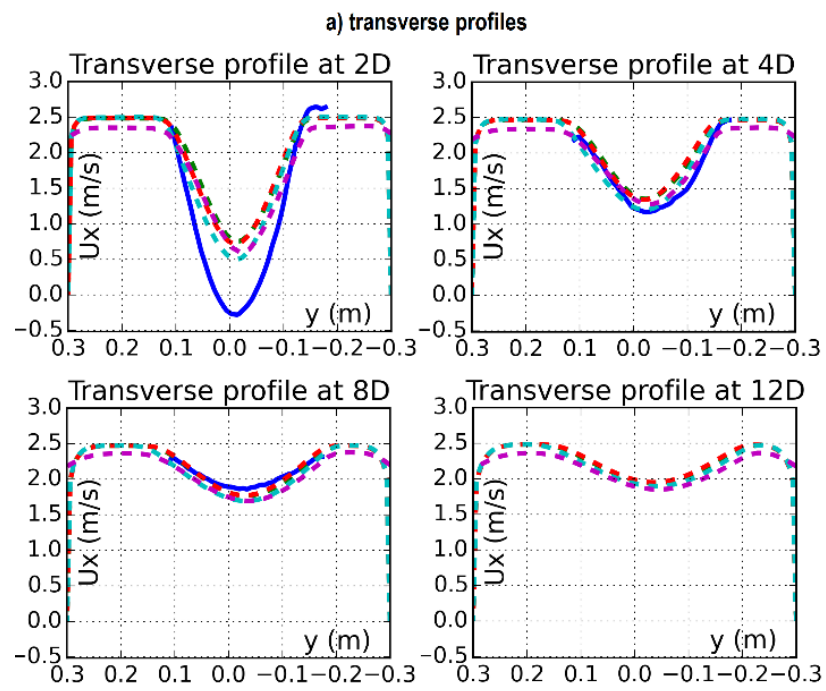

b) Vertical profiles
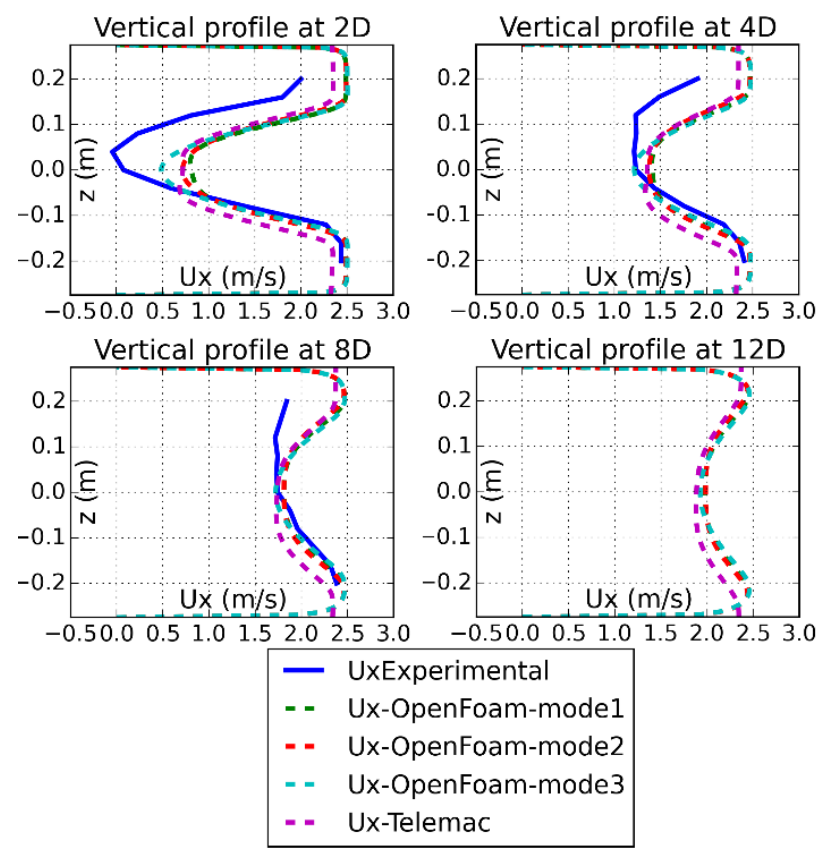

Figure 9: Transverse and vertical $U x$ profiles compared between the experiment, the three OpenFoam simulations and the TELEMAC simulation
The position of the maximum experimental velocity deficit is about $4 \mathrm{~cm}$ above the simulated ones. The asymmetric convergence at inlet might explain this drift by creating a global deviation of the flow towards the ceiling. Figure 2 shows a slightly positive z-velocity in the turbine area, supporting this theory.

All simulations tend to underestimate the velocity deficit in the near wake. However simplified models are not representing the flow exactly, as forces applied reduce the velocity locally but do not stop the flow totally like the faces of the blades do. It is normal that they present errors in the near-wake.

In the far-wake at $\mathrm{x}=8 \mathrm{D}$, relative errors on the velocity profiles are lower but the wake tends to recover slower in the simulations.

In all cases, the wake expansion is bigger in the $\mathrm{z}$ direction than in the y-direction. This phenomena still has to be analyzed.

Comparing the different simulation models, one sees almost no difference between model 1 (detailed force distribution in 3 dimensions) and model 2 (force distribution in 2 dimensions depending on the angle but not the altitude). A slight difference exists with model 3 (uniform force distribution) but it is negligible. Therefore a uniform force distribution gives correct results in the far-wake for the case $\lambda=2$. However, results might be different, especially for lower $\lambda$, where eddies on the blade might have threedimensional characteristics. The TELEMAC simulation presents a velocity offset of approximately $0.2 \mathrm{~m} / \mathrm{s}$. It can be explained in part by the inlet velocity offset present during the simulation, and by the slightly different confinement configuration. It is in good agreement with the OpenFoam simulation using the same model (model 2) considering the approximations made.

The root mean square values of the fluctuating velocities are obtained via PIV for the $\mathrm{x}$ and $\mathrm{y}$ components, for the case with regular turbulence grid. To make a comparison with simulations, the numerical $\mathrm{u}^{\text {'2 }}$ value is calculated according to the turbulent kinetic energy definition, knowing that the turbulence is isotropic in the model:

$\mathrm{k}=\frac{1}{2}\left(u^{\prime 2}+v^{\prime 2}+w^{\prime 2}\right)=\frac{3}{2} u^{\prime 2} \Rightarrow u^{\prime 2}=\frac{2}{3} \mathrm{k} \quad($ eq 5$)$

Figure 10 presents the compared transverse profiles for $\mathrm{u}^{\prime 2}$ at the same positions as before in plane 1 .

Turbulence is not isotropic in the measurements. Still, the simulated values lay between the two components measured or close to them. It allows one to state that isotropic RANS turbulence models are accurate to model the turbine wake. 


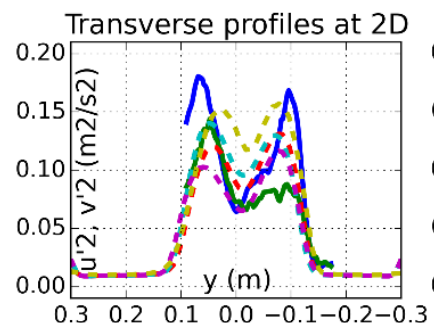

Transverse profiles at 4D

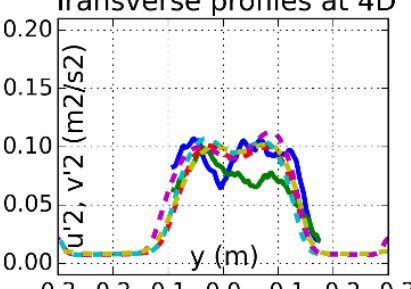

Transverse profiles at $8 \mathrm{D}$
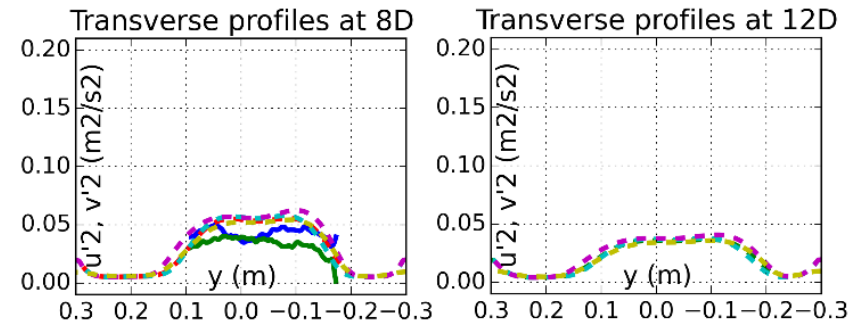

$\begin{array}{lllllllll}0.3 & 0.2 & 0.1 & 0.0-0.1-0.2-0.3 & 0.3 & 0.2 & 0.1 & 0.0 & -0.1-0.2-0.3\end{array}$

$$
\begin{array}{ll}
- & u^{\prime} 2 \text {-Experimental } \\
- & v^{\prime} 2 \text {-Experimental } \\
- & u^{\prime} 2 \text {-OpenFoam-mode1 } \\
-= & u^{\prime} 2 \text {-OpenFoam-mode2 } \\
-- & u^{\prime} 2 \text {-OpenFoam-mode3 } \\
-= & u^{\prime} 2-T e l e m a c
\end{array}
$$

Figure 10: Transverse $u^{\prime 2}$ and $v^{\prime 2}$ profiles compared between the experiment, the three OpenFoam simulations and the TELEMAC simulation

\section{Conclusion}

A simplified CFD model of a Darrieus turbine using the RANS solution method has been developed. The turbine was modeled by force source terms added to the momentum equations. The force distribution was obtained with a unique URANS full geometry simulation of the flow through the turbine. The simulated performances fitted well with those of a reduced scale Darrieus turbine tested in a hydrodynamic tunnel. A set of experimental total force curves for different ambient flow conditions impacting the turbine can be useful to correct the total forces used in the simplified model, in order to take into account flow conditions in this model. However, at the optimal operating point, the URANS simulated forces are very close to the measured ones and no correction of force is needed in the simplified model.

Measurements of the power coefficient, the axial and transverse forces applied on the turbine, and PIV-images of its wake were obtained for two different turbulence cases, with turbulence intensities of $2.5 \%$ and $5.5 \%$ respectively. For channel velocities of $2.3 \mathrm{~m} / \mathrm{s}$ and $2.8 \mathrm{~m} / \mathrm{s}$, no significant differences could be found between the two cases for the power output and forces. A small influence on the wake was observed, the velocity deficit near the machine being higher without grid. Other differences were found without turbulence grid, for a lower velocity of $1.8 \mathrm{~m} / \mathrm{s}$. It seems that the regular grid limited sensitivity to the Reynolds number. Further studies are needed with higher turbulence levels corresponding to in-situ river or tidal conditions, in order to attest the influence of a turbulent flow on a Darrieus turbine.
Different simplified models were simulated with OpenFoam and compared to measurements. At the optimal operating point $(\lambda=2)$, all models gave sensibly the same results. The forces were not dependent on the $\mathrm{z}$ direction and the experimental flow might have no component in that direction when flowing around the hydrofoil profiles of the blade. Smaller $\lambda$ might result in a 3-dimensional flow on the hydrofoil walls and require a higher-resolution model. All simplified models underestimated the velocity just behind the turbine, but were in good agreement in the area between 4 diameters and 8 diameters behind the turbine, with only a slight overestimation of the velocity deficit in the far-wake.

Finally, a simplified model simulation conducted with TELEMAC3D proved to be in good agreement with the OpenFoam simulations, even if the channel geometry could

\begin{tabular}{|c|c|c|}
\hline Symbol & Name & Unit \\
\hline $\mathrm{C}$ & Correction factor & {$[-]$} \\
\hline $\mathrm{c}$ & Chord length of hydrofoil & [m] \\
\hline $\mathrm{Cp}$ & Power coefficient & {$[-]$} \\
\hline $\mathrm{Cx}$ & Axial force coefficient & {$[-]$} \\
\hline $\mathrm{Cy}$ & Transverse force coefficient & {$[-]$} \\
\hline $\mathrm{D}$ & Diameter of the turbine & [m] \\
\hline Fx & Axial total force on the turbine & {$[\mathrm{N}]$} \\
\hline Fy & $\begin{array}{l}\text { Transverse total force on the } \\
\text { turbine }\end{array}$ & {$[\mathrm{N}]$} \\
\hline g & Gravity constant & {$\left[\mathrm{m} / \mathrm{s}^{2}\right]$} \\
\hline $\mathrm{I}_{\text {turb }}$ & Turbulence intensity & {$[-]$} \\
\hline $\mathrm{k}$ & Turbulent kinetic energy & {$\left[\mathrm{m}^{2} / \mathrm{s}^{2}\right]$} \\
\hline $\mathrm{n}$ & Blade number of the turbine & {$[-]$} \\
\hline S & Projected area of the turbine & {$\left[\mathrm{m}^{2}\right]$} \\
\hline $\mathrm{T}$ & Torque of the flow on the turbine & {$[\mathrm{Nm}]$} \\
\hline Ux & $\mathrm{X}$-component of velocity & {$[\mathrm{m} / \mathrm{s}]$} \\
\hline Uy & y-component of velocity & {$[\mathrm{m} / \mathrm{s}]$} \\
\hline $\mathrm{Uz}$ & z-component of velocity & {$[\mathrm{m} / \mathrm{s}]$} \\
\hline $\mathrm{u}^{\prime 2}$ & $\begin{array}{l}\text { Averaged square of } \mathrm{x} \text {-velocity } \\
\text { fluctuation }\end{array}$ & {$[\mathrm{m} 2 / \mathrm{s} 2]$} \\
\hline$v^{\prime 2}$ & $\begin{array}{l}\text { Averaged square of } \mathrm{x} \text {-velocity } \\
\text { fluctuation }\end{array}$ & [m2/s2] \\
\hline $\mathrm{w}^{\prime 2}$ & $\begin{array}{l}\text { Averaged square of } \mathrm{x} \text {-velocity } \\
\text { fluctuation }\end{array}$ & {$[\mathrm{m} 2 / \mathrm{s} 2]$} \\
\hline$\lambda$ & Tip speed ratio & {$[-]$} \\
\hline$\Omega$ & Rotational speed of the turbine & {$[\mathrm{rad} / \mathrm{s}]$} \\
\hline$\omega$ & Omega turbulence parameter & {$[\mathrm{s}-1]$} \\
\hline$\rho$ & Water density & {$[\mathrm{kg} / \mathrm{m} 3]$} \\
\hline
\end{tabular}
not be respected.

In the future, it is planned that the same approach will be applied on a horizontal axis tidal turbine to strengthen the methodology developed.

\section{Nomenclature}

\section{Acknowledgments}

This work is part of the ANR 3DMMTA project financed by the french 'Agence nationale de la recherche'. 


\section{References}

Aumelas V., 2011, "Modélisation des hydroliennes à axe vertical libres ou carénées : développement d'un moyen expérimental et d'un moyen numérique pour l'étude de la cavitation. "PhD thesis, Grenoble-INP.

Badalamenti C., Prince S. A., 2008, “The Effects of Endplates on a Rotating Cylinder in Crossflow", 26th AIAA Applied Aerodynamics Conference, Honolulu, Hawaii

Bertrand O., Rebai A., Girard C., 13-16 October 2015, "Development of a three-dimensional model of a vertical-axis and transverse-flow hydrokinetic turbine", 22nd Telemac \& Mascaret User Club, STFC Daresbury Laboratory, UK.

Chawdhary S., Hill C., X. Yang X., M. Guala M., Corren D., Colby J., Sotiropoulos F., 2017, "Wake characteristics of a TriFrame of axial-flow hydrokinetic turbines", Renewable Energy 109, 332-345.

De Dominicis M., O’Hara Murray R., Wolf J., 2017, "Multi-scale ocean response to a large tidal stream turbine array", Renewable Energy 114, 1160-1179.

Dominguez F., Achard J.-L., Zanette J., Corre C., 2016, "Fast power output prediction for a single row of ducted cross-flow water turbines using a BEMRANS approach", Renewable Energy 89, 658670.

Draper S., Nishino T., 2014, "Centred and staggered arrangements of tidal turbines", J. Fluid Mech., vol. 739, pp. 72-93.

Garett C., Cummins P., 2007, "The efficiency of a turbine in a tidal channel", J. Fluid Mech., vol. 588, pp. 243-251.

Gebreslassie M. G., Sanchez S. O., Tabor G. R., Belmont M. R., Bruce T., Payne G. S., Moon I., 2016, "Experimental and CFD analysis of the wake characteristics of tidal turbines", International Journal of Marine Energy 16, 209-219.

Gebreslassie M. G., Tabor G. R., Belmont M. R., 2015, "Investigation of the performance of a staggered configuration of tidal turbines using CFD", Renewable Energy 80, 690-698.

Harrison M. E., Batten W. M. J., Myers L. E., Bahaj A. S., 2009, "A comparison between CFD simulations and experiments for predicting the far wake of horizontal axis tidal turbines", Proceedings of the $8^{\text {th }}$ European Wave and Tidal Energy Conference, Uppsala, Sweden.

Kinsey T., Dumas G., 2017, "Impact of channel blockage on the performance of axial and cross-flow hydrokinetic turbines", Renewable Energy 103, 239-254.
Laan P. van der, December 2014, "Efficient turbulence modelling for CFD wake simulation", PHD report, DTU Wind Energy.

Maître T., Amet E., Pellone C., 2013, "Modeling of the flow in a Darrieus water turbine: Wall grid refinement analysis and comparison with experiments", Renewable Energy 51, 497-512.

Menter, F. R., August 1994, "Two-Equation EddyViscosity Turbulence Models for Engineering Applications", AIAA Journal, 32 (8): 1598-1605.

Menter F.R., Kuntz M., Langtry R., 2003, "Ten years of industrial experience with the SST turbulence model", Proceedings of the fourth international symposium on turbulence, heat and mass transfer, pages 625-632, Antalya, Turkey. Begell House.

Mycek P., Gaurier B., Germain G., Pinon G., Rivoalen E., 2014, "Experimental study of the turbulence intensity effects on marine current turbines behaviour. Part I: One single turbine", Renewable Energy 66, 729-746.

Myers L., Bahaj A. S., 2006, "Power output performance characteristics of a horizontal axis marine current turbine", Renewable Energy 31, 197-208.

Nguyen V. T., Guillou S. S., Thiebot J., Santa Cruz A., 2016, "Modelling turbulence with an Actuator Disk representing a tidal turbine", Renewable Energy 97, 625-635.

Nuernberg M., Tao L., 2018, "Three dimensional tidal turbine array simulations using OpenFOAM with dynamic mesh", Ocean Engineering 147, 629646.

Posa A., Parker C. M., Leftwich M. C., Balaras E., 2016, "Wake structure of a single vertical axis wind turbine", International Journal of Heat and Fluid Flow 61, 75-84.

Roc T., Conley D. C., Greaves D., 2013, "Methodology for tidal turbine representation in ocean circulation model", Renewable Energy 51, 448-464.

Shives M., Crawford C., 2015, "Validation of a practical CFD method for predicting hydrokinetic turbine performance in wake shadow", Proceedings of the 11 th european wave and tidal energy conference 6-11th september 2015, Nantes, France.

Vennell R., 2013, "Exceeding the Betz limit with tidal turbines", Renewable Energy 55, 277-285.

Vogel C.R., Willden R.H.J., Houlsby G.T., 2017, "Power available from a depth-averaged simulation of a tidal turbine array", Renewable Energy 114, 513524.

Whelan J. I., Graham J. M. R., Peir'o J., 2009, "A freesurface and blockage correction for tidal turbines", J. Fluid Mech., vol. 624, pp. 281-291.

Wimshurst A., Willden R., 2016, "Tidal power extraction on a streamwise bed slope", Ocean Engineering $125,70-81$. 